\title{
Global Seismic Hazard Assessment Program - GSHAP legacy
}

\author{
Laurentiu Danciu ${ }^{1,{ }^{\star}}$, Domenico Giardini ${ }^{2}$ \\ ${ }^{1}$ Swiss Seismological Service (SED), ETH Zurich, Switzerland \\ ${ }^{2}$ Institute of Geophysics, ETH Zurich, Switzerland
}

\author{
Article history \\ Received January 19, 2015; accepted February 6, 2015. \\ Subject classification: \\ Seismic hazard assessment, Seismic risk, Ground motion, Seismology.
}

\begin{abstract}
Global Seismic Hazard Assessment Program - or simply GSHAP, when launched, almost two decades ago, aimed at establishing a common framework to evaluate the seismic hazard over geographical large-scales, i.e. countries, regions, continents and finally the globe. Its main product, the global seismic hazard map was a milestone, unique at that time and for a decade have served as the main reference worldwide. Today, for most of the Earth's seismically active regions such Europe, Northern and Southern America, Central and South-East Asia, Japan, Australia, New Zealand, the GSHAP seismic hazard map is outdated. The rapid increase of the new data, advance on the earthquake process knowledge, technological progress, both hardware and software, contributed all in updates of the seismic hazard models. We present herein, a short retrospective overview of the achievements as well as the pitfalls of the GSHAP. Further, we describe the next generation of seismic hazard models, as elaborated within the Global Earthquake Model, regional programs: the 2013 European Seismic Hazard Model, the 2014 Earthquake Model for Middle East, and the 2015 Earthquake Model of Central Asia. Later, the main characteristics of these regional models are summarized and the new datasets fully harmonized across national borders are illustrated for the first time after the GSHAP completion.
\end{abstract}

\section{Introduction}

GSHAP [Giardini et al. 1999] was the successful initiative of elaborating a global quantitative seismic hazard map. GSHAP launched in 1992 by the International Lithosphere Program (ILP) with the support of the International Council of Scientific Unions (ICSU). Also, GSHAP served as a demonstration program in the framework of the United Nations International Decade for Natural Disaster Reduction. The successful initiative was possible due to collaborative and integration strategy adopted to connect various regional centers around the world. While GSHAP was developed with the support of international projects and organizations, national scientific agencies, and research institutions, the most important support for GSHAP originated from hundreds of individual scientists - more than 500 [Shedlock et al. 2000]. GSHAP promoted a regionally coordinated, homogeneous approach to seismic hazard evaluation. Multidisciplinary procedures were adopted to combines all at-that-time state of the practice, resources and data to assess the seismic hazard over the whole continents and finally the globe. Regional programs have been established in the first implementation phase of the project (1993-1995) with a clear aimed of developing common datasets i.e. earthquake catalogues, geological fault databases, tectonic and geological information mandatory to build a seismic hazard model. During the GSHAP second phase (1995-1998), regional centers have been expanded to cover the entire globe. Further efforts were concentrated to harmonize datasets and procedures, and later on to ensemble, the sub-regional models into a global seismic hazard model. Most of the working groups adopted a probabilistic seismic hazard assessment (PSHA) framework, and the resulted Global Seismic Hazard Map [Giardini 1999] depicts the peak ground acceleration (PGA) with $10 \%$ probability of being exceeding in 50years, and was rapidly adopted as the global reference.

\section{Why the GSHAP seismic hazard map was suc- cessful?}

Firstly, the availability of the map; together with the technical reports as well as the hazard models main elements such as catalogues, source representation, software input file are still available today after two decades since the GSHAP kick-off (online data is available at the http: / / seismo.ethz.ch/GSHAP/). Also, together with the online documentation, the methods and data used in the generation of each national or regional map used to produce the Global Seismic Hazard Map were documented in a special issue of Annali di Geofisica (December 1999). Secondly, the collaborative 
strategies, with priorities on strengthening cooperation across-borders facilitate the adoption of the GSHAP products. Since, the regional hazard models were developed for both local and international data and expertise, consensus was another element that facilitate the adoption of the GSHAP hazard regional models. Finally, the stability of the results was due the multidisciplinary procedure adopted for estimating the seismic hazard, focusing on harmonization input data sets, and up-to-that-date procedures for estimating the seismic hazard. The inclusion of national maps without smoothing discrepancies along any common borders was the key assumption on aggregating the global seismic hazard map. All these characteristics greatly contributed to the success of the GSHAP program. Longevity of the GSHAP hazard map provided the unique chance to compare the seismic hazard value versus recoded ground shaking. During the last decades, immediately after the occurrence of a destructive earthquake it has become a common practice to compare the GSHAP seismic hazard map with the instrumentally recorded ground shacking. For seismically active regions, concentrated along the tectonic plates boundaries, the seismic hazard estimates typically provides a rather adequate comparison of the two. Though, the comparison should be interpreted with care, as one should acknowledge their difference - the recorded/observed ground shaking of large magnitude earthquakes exhibit extreme values, usually affected by several factors distance, site conditions, focal mechanism, directivity effects, hanging-wall and footwall effects; whereas the probabilistically estimated seismic hazard map represents the likelihood of various levels of ground shaking over a given time period. Moreover, the occurrence of large destructive earthquakes (e.g. the $\mathrm{M}_{\mathrm{w}}$ 7.7, 2001, Gujarat, India, the $M_{w} 9.1,2004$, Sumatra-Andaman, Indonesia, the $M_{w} 7.9,2008$, Wenchuan, China, the $M_{w} 6.3$, 2011, Christchurch, New Zealand, the $M_{w}$ 7.0, 2010, Port-au-Prince, Haiti and the $\mathrm{M}_{\mathrm{w}}$ 9.0, 2011, Tohoku, Japan earthquakes) in regions of relatively low seismic hazard, raised intense discussions on reliability of the GSHAP map, and in turn to the consistency of the use of probabilistic seismic hazard analysis (PSHA) to quantify of the earthquake-ground shaking hazard [Kerr 2011, Hanks et al. 2012, Kossobokov and Nekrasova 2012, Stein et al. 2012, Wyss et al. 2012, Frankel 2013, Iervolino 2013, Bela 2014, Stirling 2014, Wong 2014]. Generally, the probabilistic approach implies the combination of the earthquake recurrence rates and ground motion empirical models (i.e. ground motion prediction equations - GMPEs). Earthquake recurrence rates are consistently used to characterize the seismic sources and represent projection in a given observation time of the past seis- micity. This projection is mainly of statistical nature, based on examining large number of events as characterized by the Gutenberg-Richter [Gutenberg and Richter 1944] recurrence law for the magnitude distribution of these earthquakes. Difficulties arise when the large magnitude earthquakes do not present themself. In other words they are missing form the aggregated earthquake catalogue, and one should search for alternative sources of information - seismically active faults, geological slip and strain rates - to adequately characterize the earthquake recurrence of moderate to large magnitude earthquakes. Retrospectively, it was long recognized during the GSHAP project the importance of complete earthquake catalogues; the need of accuracy in terms of earthquake location and size; the limitations on the historical catalogues, mostly due to difficulties on identifying reliable historical sources covering the entire globe. Giardini [1999] strongly emphasized that:

"Not even the most completed earthquake catalogue cannot characterize the seismogenic process where large earthquake return every few or tens of thousand of years, i.e. in areas of active plate interiors and diffuse continental deformation; seismic zoning attempt without sufficient background informational from geology proves to be uncertain and in many areas of the world today geology is providing the key input, allowing to associate the historical earthquakes to specific seismogenic features (through evidences from seismotectonics, paleoseismology, geomorphology, mapping of active faults, geodetic estimates for crustal deformation, remote sensing and geodynamic models), and to build alternative model of seismic zonation".

These limitations or lack of geological data, reflected in various regions of the GSHAP seismic hazard map, were inherent. The case of the 7.0 magnitude earthquake that devastated Port-au-Prince, Haiti in 2010, reflects the fact that the original datasets (earthquake catalogue mainly) necessary to build the seismic hazard model were incomplete, lacking entirely the geological information, i.e. the Enriquillo-Plantain Gardens and Septentrional-Oriente faults as well as the subduction sources [Tanner and Shepherd 1997, Frankel 2013].

Today, after two decades from its start, the GSHAP can be considered as the starting point for identification of those limitations and focus on regions where new additional geologic information, new data collection, new catalogues can make a substantial difference in earthquake recurrence rates forecast and ground shaking hazard assessment.

\section{Life after GSHAP (or 20 years after)}

During the last years, the constant increase of our understanding of the earthquake generation process, 
the availability of new data and the consolidation of the probabilistic seismic hazard methods resulted in updates of the seismic hazard models worldwide. Nowadays, for most of the seismically active regions such Europe, Northern and Southern America, Central and South-East Asia, Japan, Australia, New Zealand, the global hazard map was updated to the local, and/ or regional seismic hazard estimates. Almost a decade after the completeness of GSHAP, the Global Earthquake Model (GEM; Crowley et al. [2013]) was established to continue the vision of a global seismic hazard model. Inheriting from GSHAP the collaborative effort, involving the global scientists and stakeholders, GEM moves beyond GSHAP by seeking not only a fully harmonized, transparent and state-of-the-art global seismic hazard but a seismic risk model also. GEM envisions a basis for comparing earthquake risks across regions and across borders, hence take the necessary first step towards increased awareness and actions that reduce earthquake risk. GEM develops software and tools to assist the community, national and international level for uniform earthquake risk-evaluation and as a defensible basis for risk-mitigation plans. GEM relies on the regional initiatives to form the collaborative pillars for achieving the goal of a fully harmonized global seismic hazard model. The first regional initiatives under the collaborative umbrella of GEM were focusing on the regions of Europe, Middle East and Central Asia.

The Seismic Hazard Harmonization (SHARE) project from 2009 to 2013 aimed to develop a consistent model of seismic hazard covering Europe and Turkey [Giardini et al. 2014]. The resulted 2013 European Seismic Hazard Model (hereafter ESHM13) represents a new milestone of regional seismic hazard assessment, fully transparent and open-access to all its elements. The ESHM13 delivers a reference model of seismic ground shakings for application of the European seismic regulations for building design [CEN 2004].

The EMME (Earthquake Model of the Middle East) project [Erdik et al. 2012] set at developing a harmonized seismic hazard model for Middle East and Caucasus region. The EMME initiative has a particular importance, because GSHAP has failed to present a harmonized model for the Middle East, because politics were particularly sensitive, back then. It failed in the past, but today, EMME project delivered a harmonized seismic hazard model in line with the high-standards adopted within the European Model, and promoted by GEM. The project was coordinated by KOERI and involved local and international experts. The EMME project encompassed several modules such as the Hazard Module, Seismic Risk Module, Socio-Economic Loss Module and the development of an IT infrastructure for the integration and application of modules under consideration.

The Earthquake Model Central Asia (EMCA) Project was the third regional program to start under the GEM umbrella, and it was coordinated by the GFZPotsdam, Germany. The main goal was to develop a cross-border assessment of seismic hazard and risk in Central Asia, by integrating state-of-the art procedures and updated catalogues. Highlights of this project are presented in this special issue.

\section{What do all these regional models have in com- mon?}

Cross-border harmonization

In the context of regional seismic hazard, witch covers large-scale geographical regions of complex seismotectonic environments harmonization poses difficulties; mainly due to different timeline of the projects, different base-knowledge of the regional experts and different quality of the collected data. Common procedures were adopted aiming at achieving, or at least improving, the compatibility of different raw data (i.e. earthquake catalogue, geologic, seismotectonic, geodetic); to establish key methods from the beginning for the entire model building process (i.e definition of active faults, use of slip-rates to activity conversion for active fault characterization); to impose procedures that allow technical integration (i.e. use of open-source software, use of open-standards). Also, a common definition of the output of the seismic hazard assessment was mapped into a unified scheme. Details of the harmonization process are highlighted in the following.

\section{Improved data collection}

Within each regional project, considerable efforts were put on data collection, data editing and processing, procedures to create and define harmonized data sets, construction of the recorded variables (creation of common type-format), documentation on how estimates are generated (simplification, weighting). The newly compiled and harmonized datasets used to prepare each model include the following.

Earthquake catalogue. Figure 1 illustrates the unified harmonized earthquake catalogue spanning the Euro-Mediterranean, the Caucasus, the Middle East and the Central Asia region. The unified catalogue comprises the ESHM13 homogeneous earthquake catalogue (SHEEC - the SHARE European Earthquake Catalogue; Grünthal et al. [2013], Stucchi et al. [2013]), the uniform catalog of earthquakes in the Middle East [Zare et al. 2014] and the EMCA catalogue [Mikhailova et al. 2015, this issue]. The unified catalogue presented 


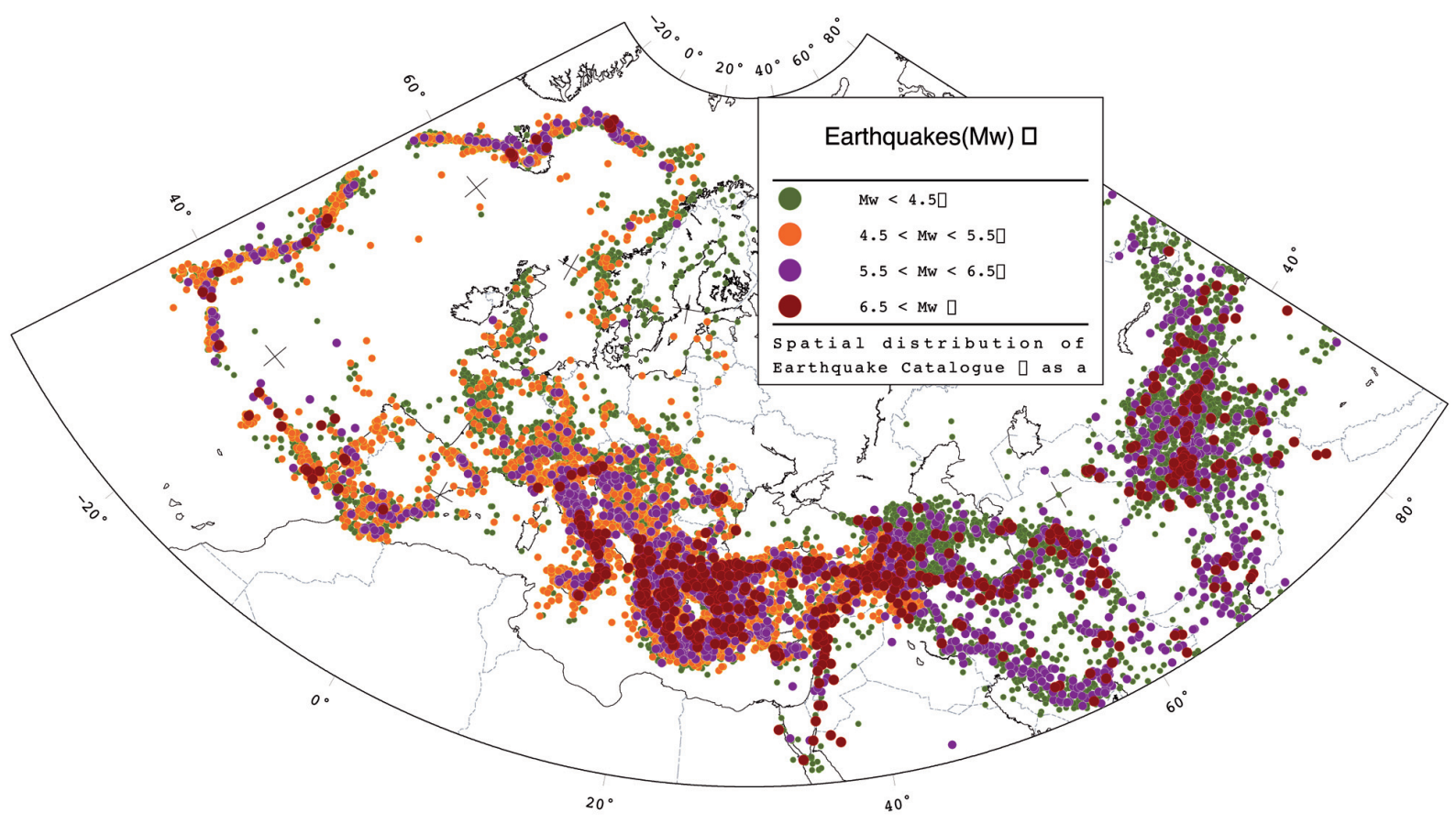

Figure 1. Unified earthquake catalogue spanning the Euro-Mediterranean, Middle and central Asia regions.

here is a result of cross-border harmonization, and regional cooperation. It is worth to mention the availability of the GEM-ICS global catalogue [Storchak et al. 2013] for the entire region, which served as an alternative source of information.

Active faults database. The availability of geologic information proved to be critical when constructing seismic hazard models. The tremendous efforts of the geologists have been materialized in the first harmonized active fault data set, fully available - the European Database of Seismogenic Faults (EDSF; Basili et al. [2013a, 2013b]). A harmonized definition of the crustal faults, the Composite Seismogenic Source (CSS) model was defined from the work of Basili et al. [2008, 2009] and adopted as the common standard for the EMME14, too. The CSS definition is versatile and covers with modifications the possibility of modeling subduction zones, specifically, the subduction interface. Figure 2 shows the unified crustal active faults for the entire region as compiled through successive stages of homogenization. These active faults were fully characterized for geometry and long-term geologic slip-rates to form independent source models. However, the geological faults in EMCA were not consider as independent seismic sources, due to limit data, but they were integrated in the definition of the area source zones.

\section{Advanced integration procedures}

The procedures of estimating the regional seismic hazard across the three geographical regions can be labeled as seismotectonic probabilism, following the description used in GSHAP. Seismotectonic probabilism, or the third generation of seismic hazard modeling, combines in a probabilistic framework the historical evidence of past earthquakes, the geologic information including paleoseismic evidences and geotectonic surface faulting as well as the scientific seismotectonic understanding of earthquake process. These evidences are combined in a source model aimed at capturing all the inherent uncertainties, our understandings and judgments involved in evaluating the input parameters of such source models. From this perspective, the three regional models were harmonized to a probabilistic framework, considering a timeindependent earthquake occurrence and adopted a logic tree framework to capture the uncertainties of future earthquake activity and strong ground motions. The ESHM13 model combines three seismic source models an area source model, a fault source model and a spatially smoothed seismicity model into a novel-weighting framework that is return time-dependent [Danciu et al. 2013]. The EMME14 model blends two seismic source models an area source model and a fault source model, whereas the EMCA source model considers the classical area source representation refined to follow geological evidences such as major seismically active faults.

Different procedures were adopted for considering the ground motion uncertainties and variability. Since GSHAP, the number of ground motion empirical models (GMPEs) was growing yearly, mainly due to the advance in network instrumentation and availability of ground motion recordings. Douglas [2014] summarizes an up-to-date list of existing GMPEs, and given this large number henceforth procedures for selecting GMPEs were necessary. The ESHM13 adopted a data-driven procedure for pre-selecting GEMPs combined with an expert elicitation procedure [Delavaud et al. 2012] to 


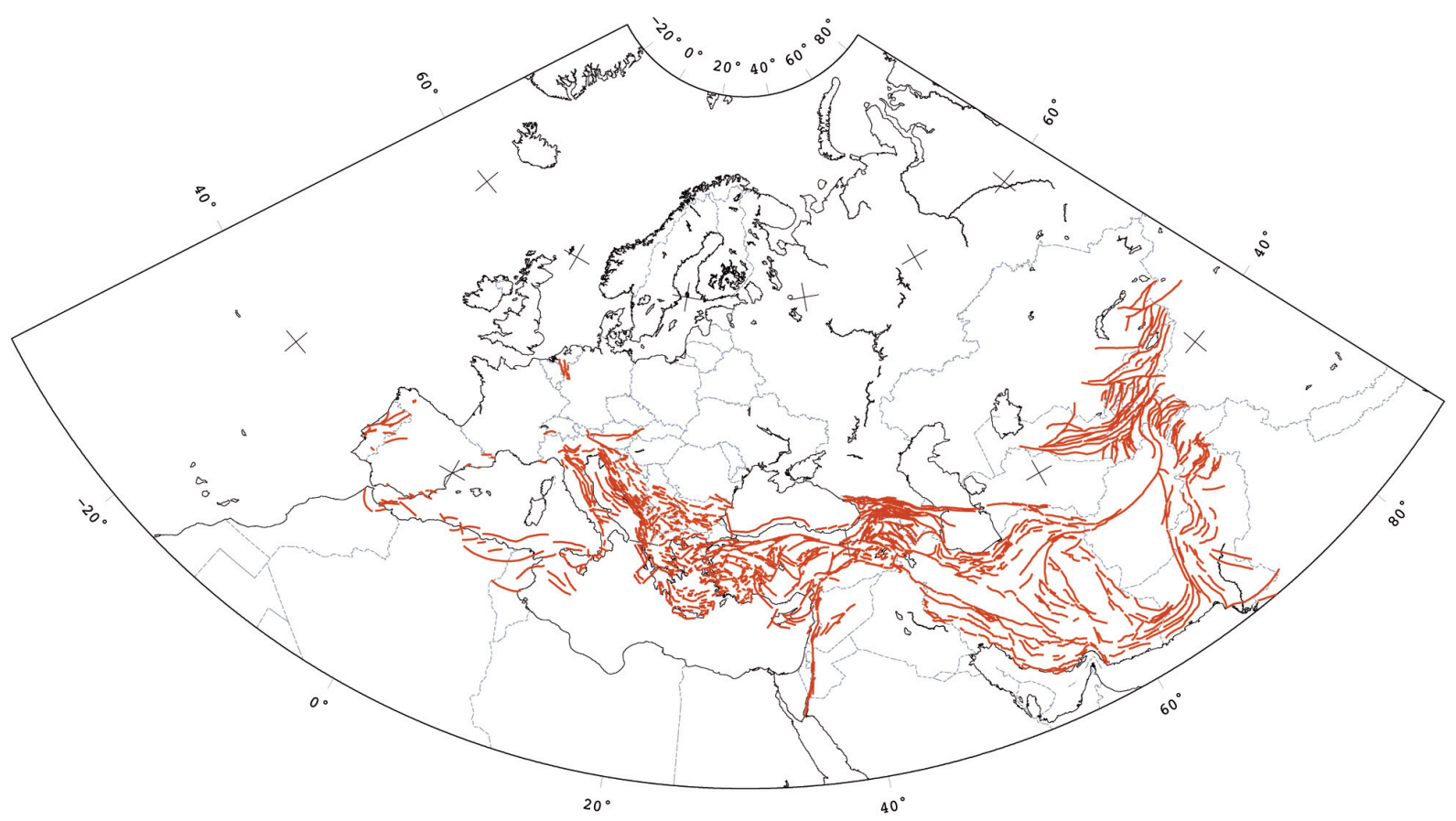

Figure 2. Unified crustal active faults for the entire region as compiled through successive harmonization procedures within ESHM13, EMM14 and EMCA.

represent the tectonic variability, the source modeling, the path and the ground motion propagation over EuroMediterranean region. EMME14 took an alternative model selection procedure combining a quantitative inspection of all GMPEs over the key model elements such as magnitude-distance pairs, focal mechanisms, and soil characterization for all spectral periods of interests. Kale and Akkar [2013] have proposed a new weighing procedure to assign the final weights to each of the selected GMPEs. Median estimates for the selected GMPEs of shallow active crust regions are illustrated in Figure 3.

Essentially, the ground motion logic trees are similar, with the replacement of the Cauzzi and Faccioli [2008] model with the Akkar et al. [2014] in the case of EMME14. The common GMPEs models are: Akkar and

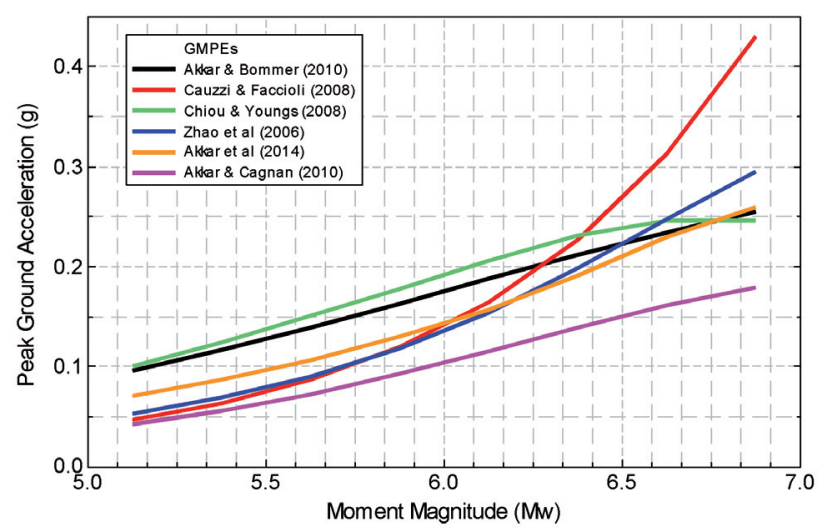

Figure 3. Median ground motion estimations for different GMPEs used to characterize the ground motion epistemic uncertainties for active shallow crust. Peak Ground Acceleration (PGA) plotted as function of different moment magnitudes for a fixed hypocentral distance of $10 \mathrm{~km}$.
Bommer [2010], Chiou and Youngs [2008] and Zhao et al. [2006]. Furthermore, the ground motion logic tree for subduction interface and inslab are identical: Atkinson and Boore [2003], Youngs et al. [1997], Lin and Lee [2008], Zhao et al. [2006] for both ESHM13 and EMME14. A different approach was considered within EMCA for ground motion characterization, which is based on macro-seismic intensity. The region has a historical tradition on estimating the seismic hazard in terms of MSK intensity, which is calibrated to the earthquake observations during the last decades. However, the local experts were aware of the limitations of using macro seismic-intensity, and there is ongoing work to investigate the use of GMPEs for the updated version of their model.

\section{State-of-the-art seismic source representation}

Past regional hazard assessment i.e. GSHAP were conducted considering seismic sources represented as point sources. PSHA was originally based on single point source representation, a description that might be appropriate for small magnitude earthquakes, but not valid earthquake source model for larger magnitudes. Large magnitude earthquakes occur on fault structures spanning over long fault ruptures, i.e. the 1999 Izmit, Turkey Earthquake $M_{w} 7.4$ had a rupture length of about $150 \mathrm{~km}$. This limitation was also due to limited modeling capabilities of the PSHA software available at that time, i.e. SEISRISK III, [Bender and Perkins 1987], FRISK88M [McGuire 2001]. Nowadays an earthquake is considered a complex finite fault rupture and the correct distance definitions based on extensive rupture are considered to reflect the advance of the new 


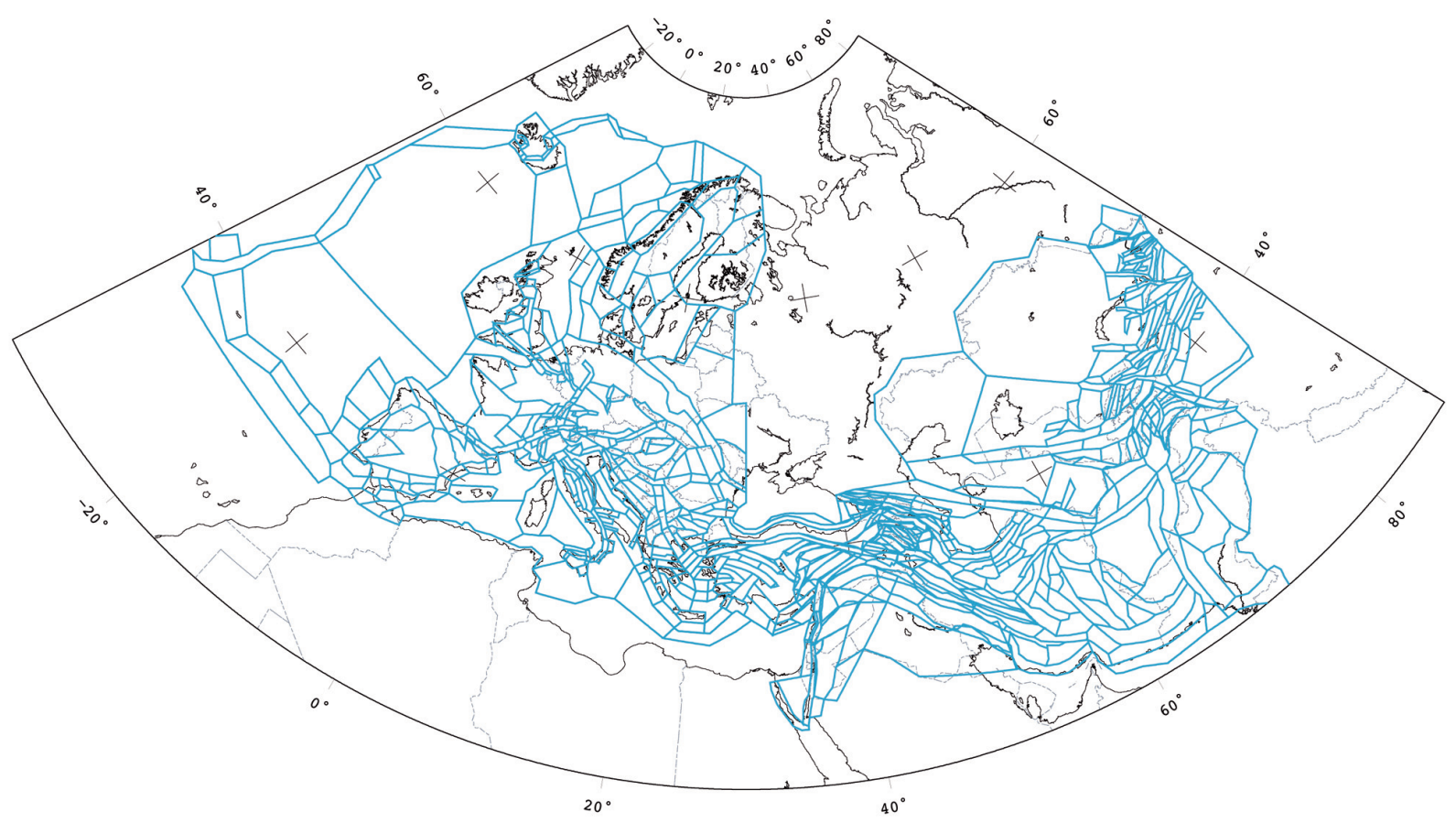

Figure 4. Seismic area source models harmonized across national border and unified within the three trans-continental models: ESHM13, EMME14 and EMCA.

ground motion models, which all integrate finite rupture-based distances. Monelli et al. [2014] illustrates the effects on the hazard estimates when considering the rupture finiteness with respect to the point-rupture approximation, which leads to a significant increase in the probabilities of exceedance for a given level of motion. A complete description of each seismic source adopted for all regional source models can be found on the OpenQuake book and user's manual [Crowley et al. 2015]. Figure 4 illustrates the seismic area source models unified over the entire region.

Open-source software, open-standards standards

OpenQuake engine [Pagani et al. 2014] represents today one of the most advanced and fully testable seismic hazard and risk software. The seismic source models of all regional models were customized and parameterized according to the OpenQuake source representation. The use of OpenQuake for seismic hazard computation facilitates the model integration across the large-scale region with the use of super-computers. OpenQuake, the input and output standards (i.e. Natural hazards and Risk Mark-up Language - NRML) were adopted as the default file formats, which will provide unique possibility of replicating entirely or partially the computational paths, review the input models and re-assess the hazard results.

\section{Dynamic results, transparency and availability}

A major drawback of GSHAP was that the uncertainties associated to the GSHAP results were neither quantitatively expressed nor explicitly documented.
Nowadays, it has become mandatory that each seismic hazard models either regional or site-specific, to present fully description of the center, body and margins of the probabilistic ground shaking estimates. For the first time, complete and harmonized seismic hazard outputs were generated for such large-scale region, spanning Euro-Mediterranean, the Caucasus, the Middle East, and the Central Asia. Seismic hazard curves, maps and uniform hazard spectra for various intensity measure types, including peak ground acceleration (PGA) and spectral acceleration (SA) were obtained. Summary statistics, such as mean, median and quantiles $(5 \%, 15 \%, 85 \%$ and $95 \%)$ are presented for all results, as a measure of the full range of uncertainties associated to the hazard results. Moreover, we are on transition from statically displayed results, such as printed maps, posters to fully accessible datasets. The ESHM13 consists of more than 500 maps displaying the ground shaking that is expected to be reached or exceeded over return periods ranging from 70 to 5000 years for more than 120,000 on-land sites equally spaced every 10 kilometers. All data and results, of ESHM13 are openly accessible online at http:/ / www. efehr.org, the portal of the European Facilities for Earthquake Hazard and Risk. The same pathway was adopted for EMME14, and in the near future, the full datasets and output are going to become publically available.

Multidisciplinary and large-scale collaborative effort

Within the GEM framework, all regional projects have closely collaborated and more than 600 seis- 


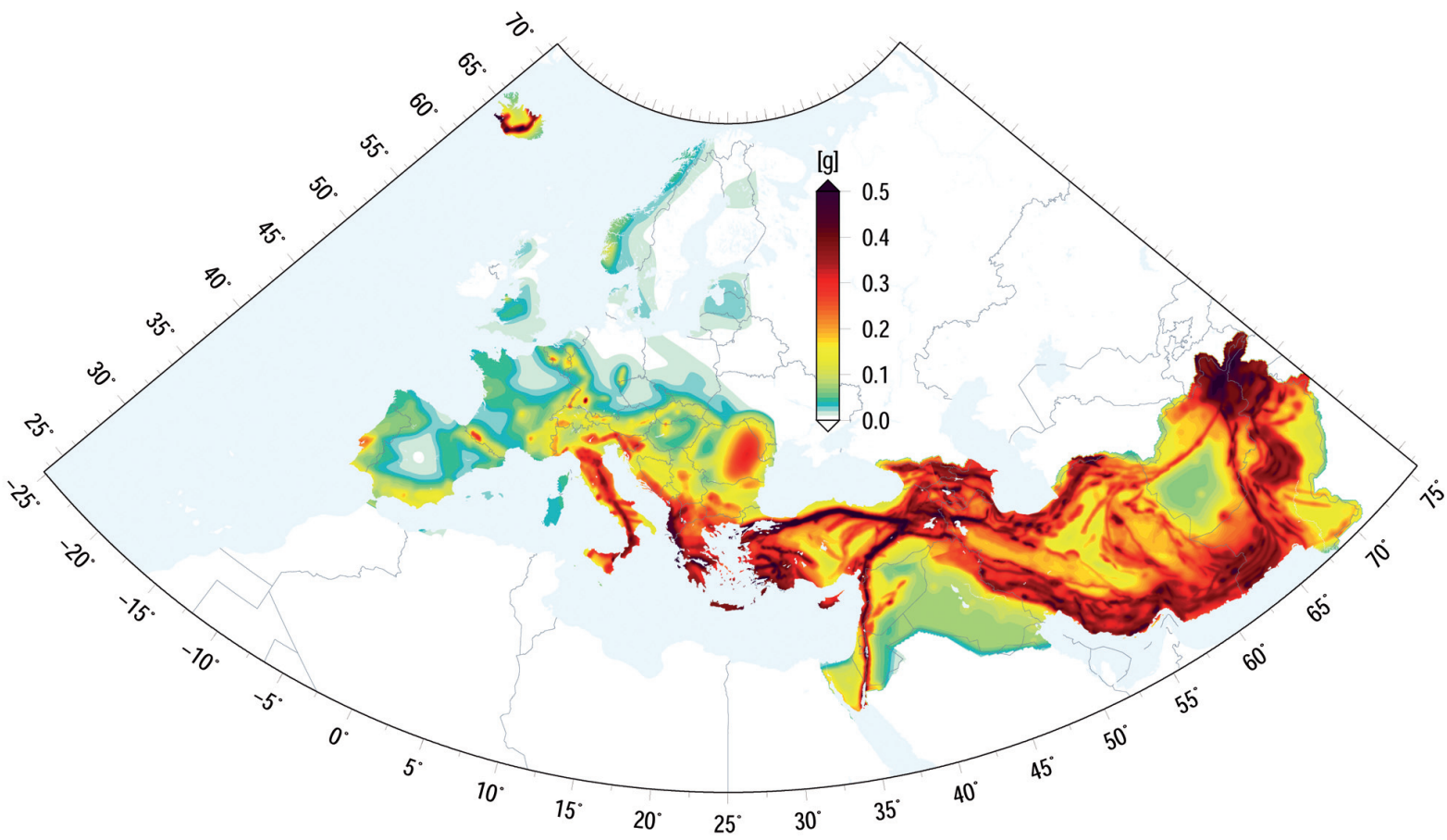

Figure 5. Harmonized seismic hazard map displaying the 10\% exceedance probability in 50years for peak ground acceleration (PGA) spanning the regions of Europe and Middle East. The seismic hazard maps for EMCA target region was produced in terms of Macroseismic intensity, hence not reproduced here.

mologists, geologists, geodesists, historians, earthquake engineers, computer scientists, statisticians, and outreach specialists formed the working core for generating state-of-the-art regional seismic hazard models.

\section{Conclusions}

Substantial progress observed during the decades in the field of seismological data collection, as a result of improvement and expansion of national seismological networks, technological advance of the instruments, and software development for data gathering, analyzing and data sharing technologies. This progress triggered the revision and updating regional seismic hazard estimates. In many regions, the long lasting GSHAP global seismic hazard map has become outdated, and as consequences new regional initiatives were established. Herein we summarized some of the key characteristics of these regional initiatives covering Europe, the Caucasus, the Middle East and the Central Asia. While, still keeping the multidisciplinary paradigm established in GSHAP, the new regional initiatives aimed at generate models fully transparent, fully reproducible and open-to access. Fully transparency of data, analytic, and developing processes of the hazard models was foreseen, as an essential foundation that allows practitioners, engineers and Earth scientists to assess/evaluate these large-scale seismic hazard models. Past regional models (including parts of GSHAP) were built by small sized group of experts, information on the model building process was insufficient, partial access to some of the input, as made the reproducibility of the results difficult; hence the usability of the model was limited to results comparison only. Moreover, we hope that latest regional GEM initiatives generated seismic hazard models that would be stable for a reasonable period of time (five to ten years) and assure longevity of their products, until significant data and information offer itself. Furthermore, the process of hazardrelevant data collection, developing data analyses and interpretations, postulating assumptions regarding data, and assumptions, testing within the technical community is time-consuming and it can be labeled as a very slow iterative process. We express our confidence that considerable attention efforts will continue the pursuit of missing information, such as buried or hidden seismically faults mostly near the urban areas, which can cause devastating earthquakes and in turn catastrophically effects to the society.

To conclude we present in Figure 5 a unified seismic hazard map depicting a $10 \%$ probability of exceedence in 50 years spanning Europe, Caucasus, Middle East and Central Asia. This map represents the first ensemble of a fully harmonized large-scale seismic hazard maps after GSHAP, and the pillar of the GEM's global seismic hazard model.

Acknowledgements. We would like to acknowledge the community beyond the GSHAP initiative, Global Earthquake Model (GEM), the SHARE Project-Consortium, EMME scientific-community and the EMCA regional collaborators for their dedication to successfully complete these projects. 


\section{References}

Akkar, S., and J.J. Bommer (2010). Empirical Equations for the Prediction of PGA, PGV, and Spectral Accelerations in Europe, the Mediterranean Region, and the Middle East, Seismol. Res. Lett., 81, 195-206; doi:10.1785/gssrl.81.2.195.

Akkar, S., M.A. Sandikkaya and J.J. Bommer (2014). Empirical Ground-Motion Models for Point- and Extended- Source Crustal Earthquake Scenarios in Europe and the Middle East, B. Earthq. Eng., 12 (1), 359-387.

Atkinson, G.M., and D.M. Boore (2003). Empirical Ground-Motion Relations for Subduction-Zone Earthquakes and Their Application to Cascadia and Other Regions, B. Seismol. Soc. Am., 93, 1703-1729.

Basili, R., G. Valensise, P. Vannoli et al. (2008). The Database of Individual Seismogenic Sources (DISS), version 3: Summarizing 20 years of research on Italy’s earthquake geology, Tectonophysics, 453, 2043; doi:10.1016/j.tecto.2007.04.014.

Basili, R., V. Kastelic, G. Valensise and DISS Working Group 2009 (2009). DISS3 tutorial series: Guidelines for compiling records of the database of the individual seismogenic sources, version 3, Rapporti Tecnici INGV, 108, 16 pp., ISSN 2039-7941.

Basili, R., V. Kastelic, M.B. Demircioglu, D. Garcia Moreno, E.S. Nemser et al. (2013a) The European Database of Seismogenic Faults (EDSF) compiled in the framework of the Project SHARE; doi:10.6092/ INGV.IT-SHARE-EDSF.

Basili, R., M.M. Tiberti, V. Kastelic et al. (2013b). Integrating geologic fault data into tsunami hazard studies, Nat. Hazards Earth Sys. Sci., 13, 1025-1050; doi:10.5194/nhess-13-1025-2013.

Bela, J. (2014). Too generous to a fault? Is reliable earthquake safety a lost art? Errors in expected human losses due to incorrect seismic hazard estimates, Earth's Future, 2, 569-578; doi:10.1002/2013EF00 0225 .

Bender, B., and D.M. Perkins (1987). SEISRISK III; a computer program for seismic hazard estimation, USGS, Open-File Report: 1772.

Cauzzi, C., and E. Faccioli (2008). Broadband (0.05 to 20 s) prediction of displacement response spectra based on worldwide digital records, J. Seismol., 12, 453475; doi:10.1007/ s10950-008-9098-y.

CEN (2004). Eurocode 8: Design of Structures for Earthquake Resistance - Part 1: General Rules, Seismic Actions and Rules for Buildings, EN 1998-1: 2004 E, Comite Europeen de Normalisation, Brussels.

Chiou, B.S.J., and R.R. Youngs (2008). An NGA Model for the Average Horizontal Component of Peak Ground Motion and Response Spectra, Earthq.
Spectra, 24, 173-215; doi:10.1193/1.2894832.

Crowley, H., R. Pinho, M. Pagani and N. Keller (2013). Assessing global earthquake risks: The Global Earthquake Model (GEM) initiative, In: S. Tesfamariam and K. Goda (eds.), Handbook of Seismic Risk Analysis and Management of Civil Infrastructure Systems, Woodhead Publishing.

Crowley, H., D. Monelli, M. Pagani, V. Silva, G. Weatherill and A. Rao (2015). The OpenQuake-engine User Manual. Global Earthquake Model (GEM) Technical Report 2015-03, 127 pp.; doi: 10.13117/ GEM. OPENQUAKE.MAN.ENGINE.1.3/01.

Danciu, L., L. Woessner, D. Giardini and SHARE Consortium (2013). A community-based Probabilistic Seismic Hazard Maps for the Euro- Mediterranean Region, In: C. Adam, R. Heuer, W. Lenhardt and C. Schranz (eds.), Vienna Congress on Recent Advances in Earthquake Engineering and Structural Dynamics 2013 - VEESD 2013 (Vienna, Austria, August 28-30, 2013), Paper no. 496.

Delavaud, E., F. Cotton, S. Akkar, F. Scherbaum, L. Danciu, C. Beauval, S. Drouet, J. Douglas, R. Basili, M.A. Sandikkaya, M. Segou, E. Faccioli and N. Theodoulidis (2012). Toward a Ground-Motion Logic Tree for Probabilistic Seismic Hazard Assessment in Europe, J. Seismol., 16 (3), 451-473.

Douglas, J. (2014). Ground motion prediction equations 1964-2014; online available: http: / /www.gmpe.org. $\mathrm{uk} /$.

Erdik, M., K. Sesetian, M.B. Demircioglu, C. Tuzun, D. Giardini, L. Gulen, S. Akkar, M. Zare (2012). Assessment of Seismic Hazard in the Middle East and Caucasus: EMME (Earthquake Model of Middle East) Project, Proceedings, 15th WCEE, Lisboa.

Frankel, A. (2013). Comment on "Why earthquake hazard maps often fail and what to do about it" by $S$. Stein, R. Geller, and M. Liu, Tectonophysics, 592, 200-206.

Giardini, D. (1999). The Global Seismic Hazard Assessment Program (GSHAP) - 1992 / 1999, Annali di Geofisica, 42 (6), 957-974; doi:10.4401/ag-3780.

Giardini, D., G. Grünthal, K.M. Shedlock and P. Zhang (1999). The GSHAP Global Seismic Hazard Map, Annali di Geofisica, 42 (6), 1225-1230; doi:10.4401/ ag-3784.

Giardini, D., J. Wössner and L. Danciu (2014). Mapping Europe's Seismic Hazard, Eos, Transactions American Geophysical Union, 95 (29), 261-262; http: / / dx. doi.org/10.1002/2014EO290001.

Grünthal, G., R. Wahlstrom and D. Stromeyer (2013). The SHARE European Earthquake Catalogue (SHEEC) for the time period 1900-2006 and its comparison to the European-Mediterranean Earthquake 
Catalogue (EMEC), J Seismol., 17, 1339-1344; doi:10. 1007/s10950-013-9379-y.

Gutenberg, R., and C.F. Richter (1944). Frequency of earthquakes in California, B. Seismol. Soc. Am., 34, 185-188.

Hanks, T.C., G.C. Beroza and S. Toda (2012). Have recent earthquakes exposed flaws in or misunderstandings of probabilistic seismic hazard analysis?, Seismol. Res. Lett., 83, 759-764.

Iervolino, I. (2013). Probabilities and fallacies: why hazard maps cannot be validated by individual earthquakes, Earthq. Spectra, 29 (3), 1125-1136.

Kale, O., and S. Akkar (2013). A new procedure for selecting and ranking ground motion prediction equations (GMPEs): The eucidean distance based ranking (EDR) method, B. Seismol. Soc. Am., 103; doi:10. $1785 / 0120120134$

Kerr, R.A. (2011). Seismic crystal ball proving mostly cloudy around the world, Science, 332, 912-913.

Kossobokov, V.G., and A.K. Nekrasova (2012). Global Seismic Hazard Assessment Program maps are erroneous, Seismic Instruments, 48 (2), 162-170.

Lin, P.-S., and G.-T. Lee (2008). Ground-Motion Attenuation Relationships for Subduction-Zone Earthquakes in Northeastern Taiwan, B. Seismol. Soc. Am., 98, 220-240; doi:10.1785/0120060002.

McGuire, R.K. (2001). FRISK-88M User's Manual, Risk Engineering Inc., Boulder, Colorado, USA.

Mikhailova, N.N., A.S. Mukambayev, I.L. Aristova, G. Kulikova, S. Ullah, M. Pilz and D. Bindi (2015). Central Asia earthquake catalogue from ancient time to 2009, Annals of Geophysics, 58 (1), S0102; doi:10.44 $01 /$ ag-6681.

Monelli, D., M. Pagani, G. Weatherill, L. Danciu and J. Garcia (2014). Modeling Distributed Seismicity for Probabilistic Seismic-Hazard Analysis: Implementation and Insights with the OpenQuake Engine, B. Seismol. Soc. Am., 104 (4), 1636-1649; doi:10.1785/ 0120130309.

Pagani, M., D. Monelli, G. Weatherill, L. Danciu, H. Crowley, V. Silva, P. Henshaw, L. Butler, M. Nastasi, L. Panzeri, M. Simionato and D. Viganò (2014). OpenQuake-engine: An open hazard (and risk) software for the Global Earthquake Model, Seismol. Res. Lett., 85, 692-702; doi:10.1785/ 0220130087.

Shedlock, K.M., D. Giardini, G. Grünthal and P. Zhang (2000). The GSHAP global seismic hazard map, Seismol. Res. Lett., 71 (6), 679-689.

Stein, S., R. Geller and M. Liu (2012). Why earthquake hazard maps often fail and what to do about it, Tectonophysics, 562/563, 1-25.

Stirling, M.W. (2014). The Continued Utility of Probabilistic Seismic-Hazard Assessment, Earthquake
Hazard, Risk and Disasters, 359-376; doi:10.1016/ B978-0-12-394848-9.00013-4.

Storchak, D.A., D. Di Giacomo, I. Bondár, E.R. Engdahl, J. Harris, W.H.K. Lee, A. Villaseñor and P. Bormann (2013). Public Release of the ISC-GEM Global Instrumental Earthquake Catalogue (1900-2009), Seismol. Res. Lett., 84 (5), 810-815; doi:10.1785/ 022 0130034.

Stucchi, M., A. Rovida, A.A. Gomez Capera, P. Alexandre, T. Camelbeeck, M.B. Demircioglu, P. Gasperini, V. Kouskouna, R.M.W. Musson, M. Radulian, K. Sesetyan, S. Vilanova, D. Baumont, H. Bungum, D. Fäh, W. Lenhardt, K. Makropoulos, J.M. Martinez Solares, O. Scotti, M. Živcic, P. Albini, J. Batllo, C. Papaioannou, R. Tatevossian, M. Locati, C. Meletti, D. Viganò and D. Giardini (2013). The SHARE European Earthquake Catalogue (SHEEC) 1000-1899, J. Seismol., 17, 523-544.

Tanner, J.G., and J.B. Shepherd (1997). Seismic hazard in Latin America and the Caribbean. Project Catalog and Seismic Hazard Maps, vol. 1, International Development Research Centre, Ottawa, $143 \mathrm{pp}$.

Youngs, R.R., S.J. Chiou, W.J. Silva and J.R. Humphrey (1997). Strong Ground Motion Attenuation Relationships for Subduction Zone Earthquakes, Seismol. Res. Lett., 68, 58-73; doi:10.1785/gssrl.68.1.58.

Zare, M., H. Amini, P. Yazdi, K. Sesetyan, M.B. Demircioglu, D. Kalafat, M. Erdik, D. Giardini, M.A. Khan and N. Tsereteli (2014). Recent developments of the Middle East catalog, J. Seismol., 18 (4), 749-772; http: / / dx.doi.org/10.1007/s10950-014-9444-1.

Zhao, J.X., J. Zhang, A. Asano, Y. Ohno, T. Oouchi, T. Takahashi, H. Ogawa, K. Irikura, H.K. Thio, P.G. Somerville, Y. Fukushima and Y. Fukushima (2006). Attenuation Relations of Strong Ground Motion in Japan Using Site Classification Based on Predominant Period, B. Seismol. Soc. Am., 96, 898-913; doi: $10.1785 / 0120050122$.

Wong, I.G. (2014). How big, how bad, how often: are extreme events accounted for in modern seismic hazard analyses?, Nat. Hazards, 72 (3), 1299-1309.

Wyss, M., A. Nekrasova and V. Kossobokov (2012). Errors in expected human losses due to incorrect seismic hazard estimates, Nat. Hazards, 62 (3), 927-935; doi:10.1007/s11069-012-0125-5.

Corresponding author: Laurentiu Danciu, Swiss Seismological Service (SED), ETH Zurich, Switzerland; email: laurentiu.danciu@sed.ethz.ch.

(C) 2015 by the Istituto Nazionale di Geofisica e Vulcanologia. All rights reserved. 